\title{
Design and Implementation of Prototype for Portable and Wireless EEG Device
}

\author{
Hasan Bitar ${ }^{1}$, Cengiz Tepe ${ }^{2 *}$ \\ ${ }^{1}$ Ondokuz Mayıs University, Faculty of Engineering, Department of Electrical-Electronics Engineering, Samsun, Turkey, (ORCID: 0000-0003-3190-2034), \\ hasan4academic@gmail.com \\ 2* Ondokuz Mayıs University, Faculty of Engineering, Department of Electrical- Electronics Engineering, Samsun, Turkey, (ORCID: 0000-0003-4065-5207), \\ cengiztepe1@gmail.com
}

(International Symposium on Multidisciplinary Studies and Innovative Technologies (ISMSIT) 2021 - 21-23 October 2021)

(DOI: 10.31590/ejosat.1016694)

ATIF/REFERENCE: Bitar, H., \& Tepe, C. (2021). Design and Implementation of Prototype for Portable and Wireless EEG Device. European Journal of Science and Technology, (29), 225-230.

\begin{abstract}
Electroencephalography (EEG) measurement system is used in the health field for the diagnosis of some diseases, and the improvement of the learning process. In this study, an embedded system consisting of two parts, hardware and software has been designed and implemented for processing and displaying the EEG signal. In the hardware section, electronic circuit design and implementation are provided for measuring, amplifying, filtering, extracting EEG rhythms, and wirelessly transmitting the EEG signal. In the software section, a smartphone application interface is developed for that the measured raw EEG signal and rhythms can be displayed in real-time.
\end{abstract}

Keywords: EEG, Portable EEG device, Wireless data transmission, EEG signal monitoring system.

\section{Taşınabilir ve Kablosuz EEG Cihazı Prototibi Tasarımı ve Gerçeklemesi}

\section{Öz}

Elektroensefalografi (EEG) ölçüm sistemi, sağlık alanında bazı hastalıkların teşhisinde ve öğrenme sürecinin iyileştirilmesinde kullanılmaktadır. Bu çalışmada EEG işaretinin işlenmesi ve görüntülenmesi için donanım ve yazılım olmak üzere iki bölümden oluşan bir gömülü sistem tasarımı ve gerçeklemesi yapılmışıtır. Donanım bölümünde EEG işaretinin ölçülmesi, yükseltilmesi, süzgeçlenmesi, ritimlerinin çıkarılması ve kablosuz olarak gönderilmesi için elektronik devre tasarımı ve gerçeklemesi sağlanmıştır. Yazılım bölümünde ise ölçülen ham EEG işaretinin ve ritimleri gerçek zamanlı görüntülenmesi için akıllı cep telefonu uygulaması yerli arayüzü yazılmıştır.

Anahtar Kelimeler: EEG, Taşınabilir EEG cihazı, Kablosuz veri aktarımı, EEG işareti görüntüleme sistemi.

\footnotetext{
*Corresponding Author: cengiztepe1@gmail.com
} 


\section{Introduction}

Due to the rhythmic behavior of neurons in the human cerebral cortex, electrical potential changes in the cerebral cortex can be detected by electrodes placed on the scalp, and the EEG signal is obtained from the measurement of these changes. The EEG signal can be used in the field of health for the diagnosis of insomnia, brain death, coma cases, and some diseases such as epilepsy, in various fields such as educational processes by examining the level of attention in the learning process, and Biomedical engineering applications (Ni et al., 2020; Şahin, 2015).

In the past, because of the large size and cost of EEG devices, patients had to go to hospitals in cities to record their EEG signals. Efforts have been made to reduce the size of the EEG device and to use it in wider fields. In the studies in the literature, portable EEG signal acquisition systems are mostly designed to be wired and the acquired signal can be transmitted to the computer via the serial port (Engin et al., 2007; Şahin, 2015). In the other study, a portable wireless EEG recording system was designed and implemented. However, in the wireless section, a Zigbee module is used and the information is sent to the computer (Chen and Wang, 2011). In some studies, instrumentation hardware and software of an EEG-based braincomputer interface (BCI) has been implemented (Bueno et al., 2013; Günaydın, 2010). In many studies, EEG kits or devices have been used as hardware part (Song et al., 2012). Some studies have developed a system for analyzing EEG signals, but they haven't extracted EEG rhythms (EL Menshawy et al., 2015). In another study, Python programming language and Labview program were used to implement an 8-channel EEG measuring device and to process the received EEG signal in the computer environment by software (Balım, 2018).

In this study, an embedded system processes and displays EEG signals is designed and implemented. This system consists of two parts, hardware and software. In the hardware part, instrumentation amplification, filtering, main amplification, and conversion analog signal to digital process is handled by the STM32F103 microcontroller. In addition at this stage, five signals are obtained from the raw EEG signal acquired, which are EEG frequency sub-bands Alpha, Beta, Delta, Gamma, and Theta signals. The next step is wirelessly transmitting to a smartphone that can be connected to this system via the Bluetooth module. In the software section, a smartphone application's interface is developed and the raw state of the EEG signal and frequency sub-bands are displayed in real-time through this interface.

The designed prototype is a portable, cost-effective, wireless EEG device that transmits the EEG signal and has a unique mobile application to display it.

\section{Material and Method}

In this study the parts of the design of the system as can be seen in Figure 1, first in the hardware part, EEG signal is acquired then filtering the signal, converting it from analog to digital, after that processing it and transferring it to the smartphone wirelessly via the Bluetooth unit. The second part is about software, this part contains a smartphone application interface for displaying the transmitted EEG signal.

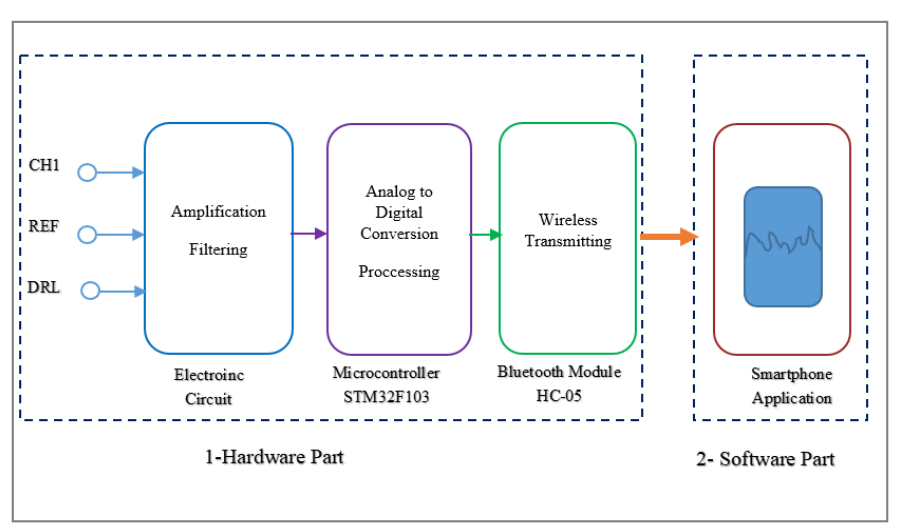

Figure 1. Block diagram of the designed EEG system

\subsection{Hardware Architecture of the System}

The amplitude of the EEG signal is very low and noisy, usually affected by the power line noise, Electromyography (EMG), and Electrocardiography (ECG) signals (Thenappan et al., 2021). For this reason, the EEG signal must be amplified to be measured, then filtered, and the amplifier to be used for this application must have important features. First, the amplifier is selective to the biological signal. It also blocks superimposed noise and interference signals. Second, it provides protection for both the person and the electronic equipment from damage through voltage and current surges (Bronzino, 2006). Considering these features, the hardware part of the system has been prepared. Figure 2, shows the hardware part block diagram.

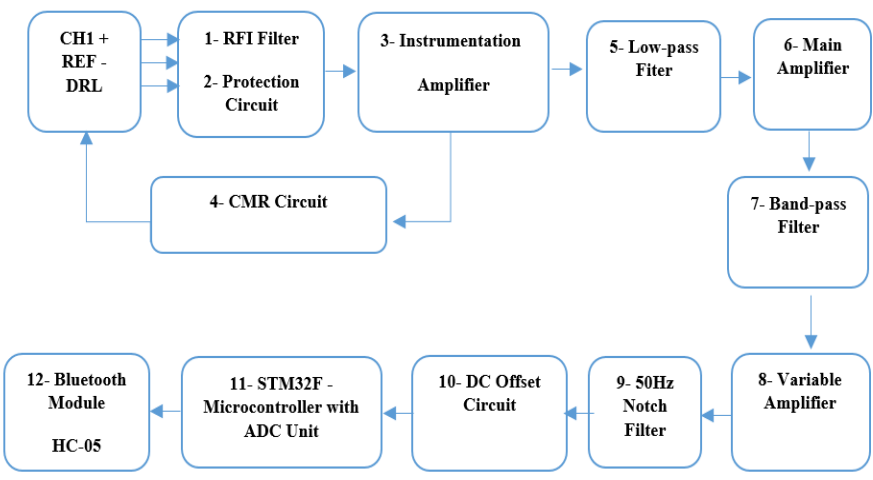

Figure 2. Block diagram of the hardware architecture of the system

In this design, three electrodes made of silver chloride $(\mathrm{AgCl})$ material are used. The EEG signal is acquired with two bipolar $\mathrm{AgCl}$ electrodes, which are connected to $\mathrm{CH} 1+$ and $\mathrm{REF}$ terminals, the third electrode is connected to the driven-right-leg DRL terminal for the common-mode rejection (CMR). The detected signal by $\mathrm{AgCl}$ electrodes is first passed through a radio frequency interference (RFI) filter and protection circuit. The next major step is amplifying signal amplitude approximately 13.5 times with an instrumentation differential amplifier. The purpose of the CMR circuit is to minimize the effect of unwanted common-mode signals such as $50 \mathrm{~Hz}$ frequency signal and noise signal. In the next step, the DC Offset coefficient is filtered by a low-pass filter with a cutoff frequency of $0.1 \mathrm{~Hz}$. The power of the signal is increased by about 51 times by the second main amplifier. Then, a $0.23-102.43 \mathrm{~Hz}$ band-pass filter was used. This filter minimizes DC interference and baseline 226 
drift. The gain of the third amplifier can be adjusted as desired. In the next step, the EEG signal is passed through the $50 \mathrm{~Hz}$ notch filter circuit (Zhang et al., 2013). After that, the negative values of the filtered analog signal are shifted to the positive direction with the DC Offset circuit in order to be read by the microcontroller. Finally, the analog-digital converter (ADC) unit of the STM32F103 microcontroller is used to convert the signal from analog to digital. The EEG signal is processed by this microcontroller and separated into Alpha, Beta, Gamma, Delta, and Theta rhythms. After processing, it is sent to the smartphone using the Bluetooth module $\mathrm{HC}-05$ via the serial port.

The PCB layout, three-dimensional image, and physical final state of the two-layer printed circuit of the electronic circuit that performs the operations mentioned in this section are shown in Figure 3.
During the processing of the EEG signal by the microcontroller, digital Butterworth bandpass filters type are applied to decompose the EEG signal into frequency sub-bands. The advantage that prompted us to choose a Butterworth filter is its flat response and no ripple. EEG rhythms and frequency subbands are indicated in Table 1 (Kropotov, 2009).

Finally, the processed signal is transmitted via the serial port of the microcontroller. The baud rate is set to $115,200 \mathrm{bit} / \mathrm{sec}$ in order to provide fast signal transmission via the Bluetooth module which is connected to the serial port. The signal sent from the Bluetooth module can be received by a smartphone that has a Bluetooth feature.

Table 1. EEG rhythms and frequency sub-bands

\begin{tabular}{c|c}
\hline Rhythm & Frequency Sub-band [Hz] \\
\hline Delta & $1-4$ \\
\hline Theta & $4-8$ \\
\hline Alpha & $8-13$ \\
\hline Beta & $13-30$ \\
\hline Gamma & $>30$ \\
\hline
\end{tabular}

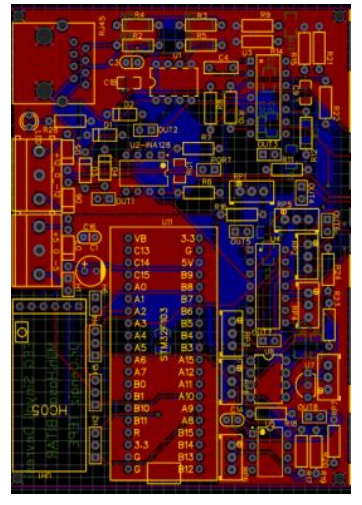

(a)

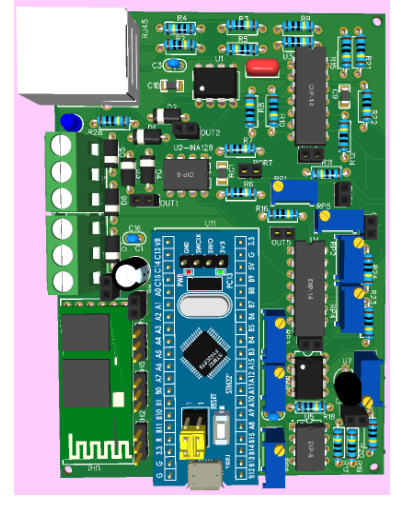

(b)

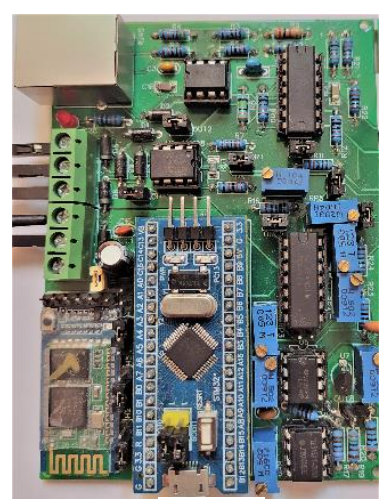

(c)
Figure 3. (a) PCB layout of the designed electronic circuit, (b) 3D image, and (c) physically implemented printed circuit

\subsection{Software Part of The System}

In this section, a smartphone application interface has been developed. Two screenshots of the interface of the developed application are shown in Figure 4.
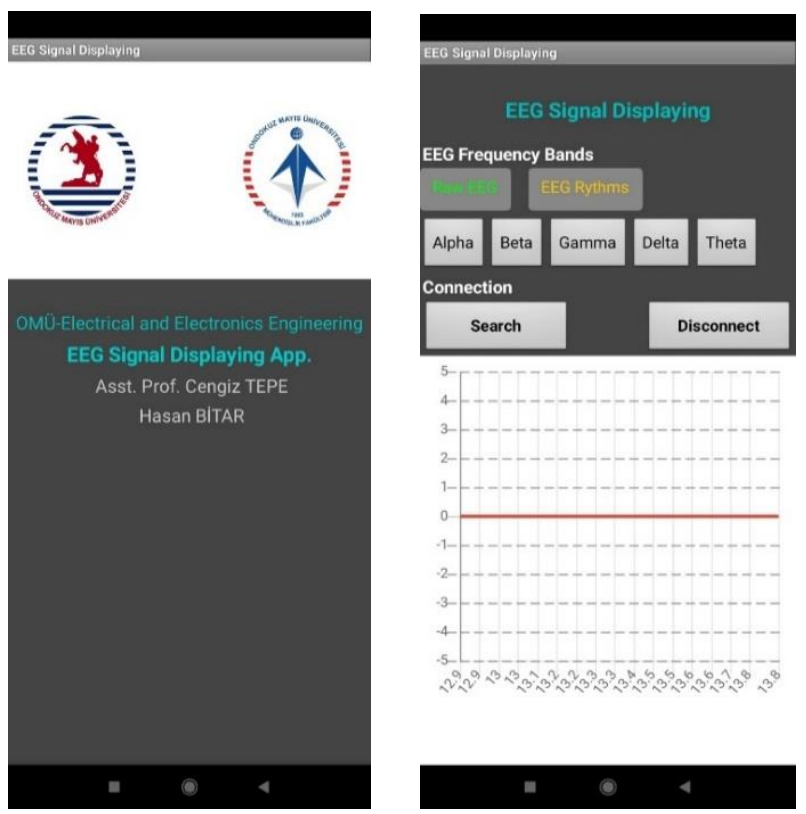

Figure 4. The developed application's interface

In this interface, the EEG signal sent from the hardware unit via the Bluetooth module, the raw state, or one of the five frequency sub-bands of the EEG signal defined in Section 2.1 can be displayed. 
Figure 5. shows a flowchart of the algorithm implemented in this section. In order to pair with the HC-05 Bluetooth module first, the $\mathrm{HC}-05$ option is selected from the menu that appears by pressing the search button in the interface. After confirming that the connection is complete, the raw EEG signal is requested from the microcontroller by default, after that, we can choose the signal type from the interface and select a frequency sub-band for the EEG signal. Then data from the microcontroller is added to a matrix. After that, the data is converted to corresponding voltages, in volts. Finally, the EEG signal amplitude values, in volts, are plotted on the vertical axis of the graph and time values in milliseconds are plotted on the horizontal axis of the graph.

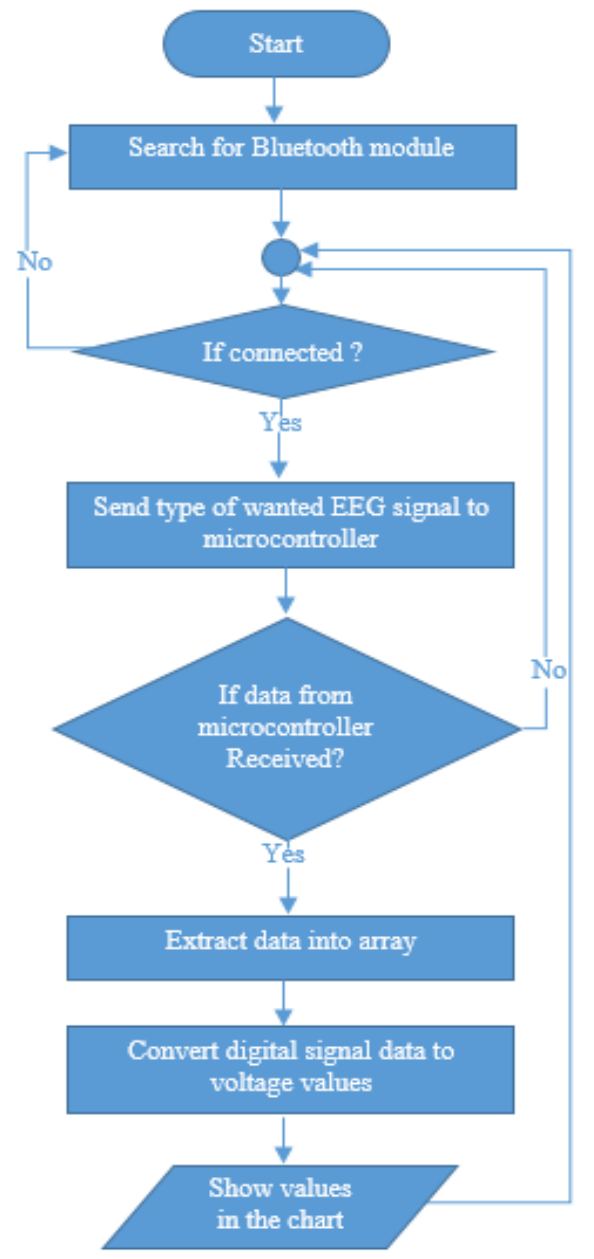

Figure 5. Flow chart of smartphone software algorithm

\section{Results and Discussion}

In order to test the prototype of the EEG device designed in this study, three electrodes that can be connected to the circuit were placed, according to the (10-20 Electrode Placement System), $\mathrm{CH} 1+$ electrode in FP1 place, REF- and DRL electrodes in A1 and A2 places respectively. The smartphone application, developed to show the raw state of the EEG signal and frequency sub-bands, has been installed. The desired signal type is selected from the application's interface. As a result, the raw EEG signal or one of the rhythms is shown on the graph in the interface.
The results of the experiment are shown in Figure 6 and Figure 7. Screenshots showing the raw EEG signal and rhythms Alpha, Beta, Delta, Gamma, and Theta graphics were added from the developed interface.

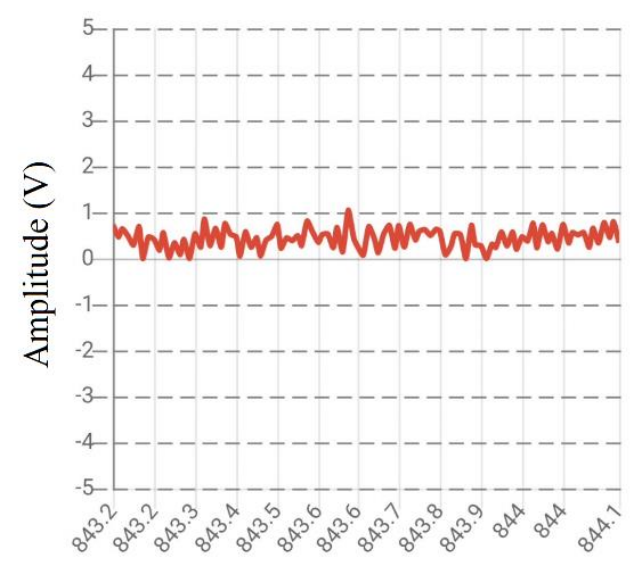

Time (ms)

(a)

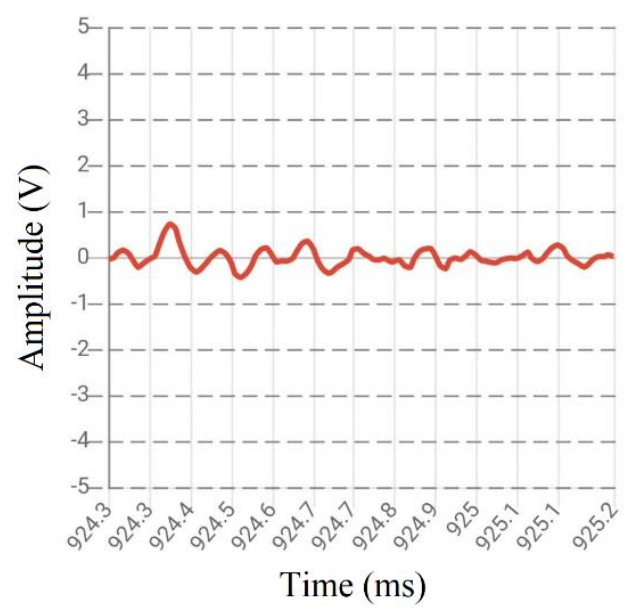

(b)

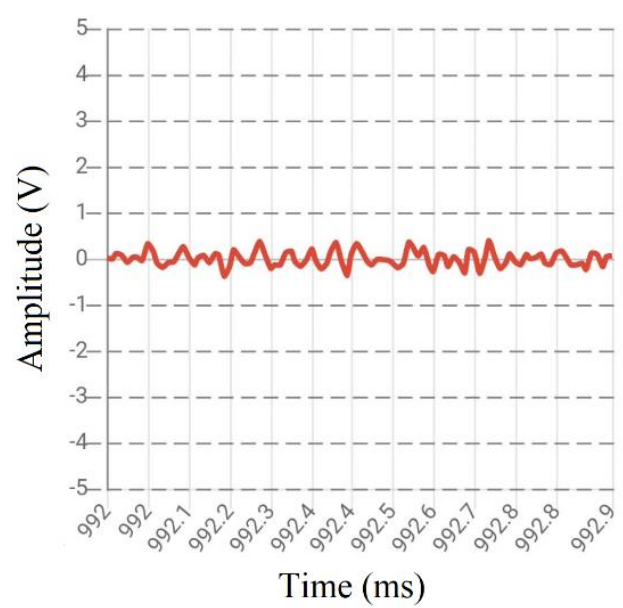

(c)

Figure 6. Graphs of the obtained EEG signal (a) Raw state, (b) Alpha rhythm, and (c) Beta rhythm 


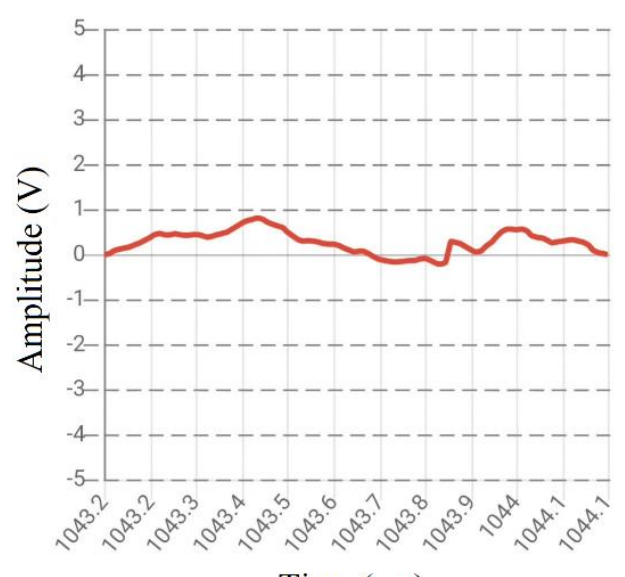

Time (ms)

(a)

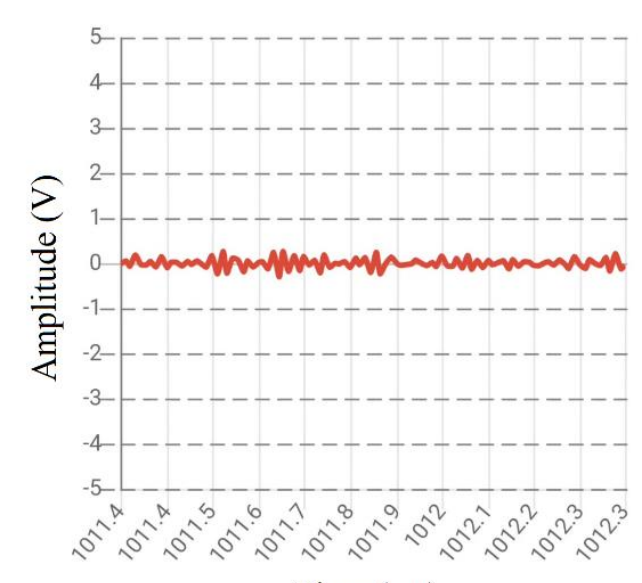

Time (ms)

(b)

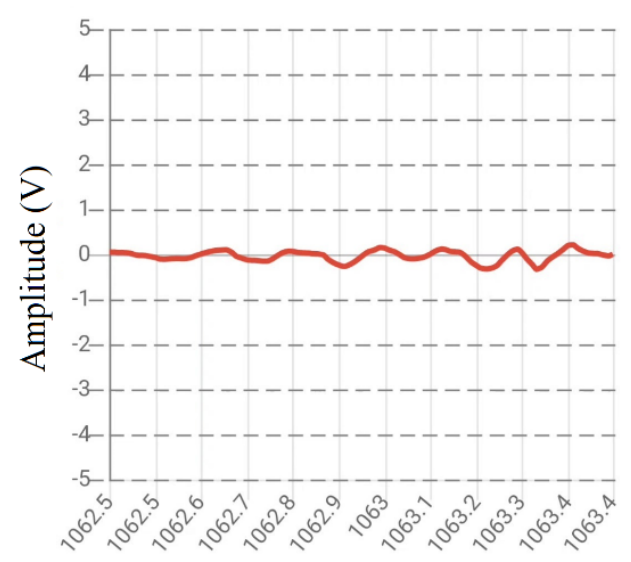

Time (ms)

(c)

Figure 7. Graphs of the obtained EEG signal (a) Delta rhythm, (b) Gamma rhythm, and (c) Theta rhythm

In many studies in the literature, interface designs that only work in computer environment have been made by using Processing program (Şahin, 2015), Bioexplorer software (Engin et al., 2007), Python programming language and Labview program (Balım, 2018). At the same time, multi-channel amplifier circuits (Balım, 2018; Chen and Wang, 2011) and commercially available electronic cards (Song et al., 2012) were used in these studies. In this study, a smartphone application interface has been developed. In addition, a new single-channel, portable, cost-effective EEG data acquisition card has been designed and implemented. Thus, this device will be given to patients in cases where they cannot come to the hospital due to old age or pandemic diseases such as COVID 19, thus providing a great convenience from EEG recordings. Because most family members have smartphones. It will only be enough for the individual to download the application to their mobile phone.

\section{Conclusions and Recommendations}

In this study, a single-channel, portable, and cost-effective EEG device prototype with hardware and smartphone interface was designed and implemented for EEG signals acquisition and extracting rhythms. In the developed interface, the raw EEG signal and five frequency sub-bands, Alpha, Beta, Delta, Gamma, and Theta signals; obtained from the EEG signal are also displayed in real-time.

In future studies, it is aimed that the EEG data in the interface will be transferred to the cloud system so that physicians with internet access can access this data remotely. In addition, it is planned to obtain the attention or meditation information of individuals from the EEG signal in real-time and display it as a percentage value in the interface.

\section{References}

Balım, M. A. (2018). 8 Kanallı Taşınabilir EEG Ölçüm Cihazı [Master's thesis, Bursa Technical University]. Yüksek Öğretim Kurulu Ulusal Tez Merkezi. https://tez.yok.gov.tr/UlusalTezMerkezi/tezDetay.jsp?id=TpC MYmF_t0cWrHsbO4XAQQ\&no=c3dfJ_3ZO9am7F6NaqlU $\mathrm{rQ}$

Bronzino, J. D. (2006). The Biomedical Engineering Handbook, (3rd ed.). CRC Press.

Bueno, L., Pons, J. L., \& Bastos Filho, T. F. (2013). An embedded system for an EEG based BCI. 2013 ISSNIP Biosignals and Biorobotics Conference: Biosignals and Robotics for Better and Safer Living (BRC), 1-5. https://doi.org/10.1109/BRC.2013.6487457

Chen, X., \& Wang, Z. J. (2011). Design and implementation of a wearable, wireless EEG recording system. 2011 5th International Conference on Bioinformatics and Biomedical Engineering,

$1-4$. https://doi.org/10.1109/icbbe.2011.5781501

EL Menshawy, M., Benharref, A., \& Serhani, M. (2015). An automatic mobile-health based approach for EEG epileptic seizures detection. Expert Systems with Applications, 42(20), 7157-7174. https://doi.org/10.1016/j.eswa.2015.04.068

Engin, M., Dalbast1, T., Güldüren, M., Davasl1, E., \& Engin, E. Z. (2007). A prototype portable system for EEG measurements. Measurement, 40(9-10), 936-942. https://doi.org/10.1016/j.measurement.2006.10.018

Günaydın, O. (2010). Design Of A Brain Computer Interface (BCI) System Based On Electroencephalogram (EEG) [Master's thesis, Boğaziçi University]. Yüksek Öğretim Kurulu Ulusal Tez Merkezi. https://tez.yok.gov.tr/UlusalTezMerkezi/tezDetay.jsp?id=f85 
Ehi2ivyvosYC4EkCiAQ\&no=eYV1BVAsSBk77KpRZq $8 \mathrm{E}$

$\mathrm{w}$

Kropotov, J. D. (2009). Quantitative EEG, Event-Related Potentials and Neurotherapy. Elsevier. https://doi.org/10.1016/B978-0-12-374512-5.X0001-1

Ni, D., Wang, S., \& Liu, G. (2020). The EEG-Based Attention Analysis in Multimedia m-Learning. Computational and Mathematical Methods in Medicine, 2020, 4837291. https://doi.org/10.1155/2020/4837291

Song, W., Yu, H., Liang, C., Wang, Q., \& Shi, Y. (2012). Body monitoring system design based on android smartphone. 2012 World Congress on Information and Communication Technologies, 1147-1151. https://doi.org/10.1109/WICT.2012.6409247

Şahin, M. (2015). EEG Sinyali Almak İçin Sistem Tasarımı [Master's thesis, Bozok University]. Yozgat Bozok University Dspace. http://dspace.bozok.edu.tr/xmlui/bitstream/handle/11460/436 /413227.pdf

Thenappana S., Nagarajanb R., \& Kannadhasanc S. (2021). Performance Improvement in Electroencephalogram Signal by Using DWT. Turkish Journal of Computer and Mathematics Education, 12(10), 2770-2775. https://doi.org/10.17762/turcomat.v12i10.4895

Zhang, L., Guo, X., Wu, X., \& Zhou, B. (2013). Low-cost circuit design of EEG signal acquisition for the brain-computer interface system. 2013 6th International Conference on Biomedical Engineering and Informatics, 245-250. https://doi.org/10.1109/BMEI.2013.6746942 